\title{
Restoration Prospects for Heitutan Degraded Grassland in the Sanjiangyuan
}

\author{
LI Xi-lai1* ${ }^{*}$, PERRY LW George ${ }^{2,3}$, BRIERLEY Gary ${ }^{2}$, GAO Jay², ZHANG Jing1, YANG Yuan-wu1 \\ 1 College of Agriculture and Animal Husbandry, Qinghai University, Xining 810o16, China \\ 2 School of Environment, University of Auckland, New Zealand Private Bag 92019, Auckland, New Zealand \\ 3 School of Biological Sciences, University of Auckland, New Zealand Private Bag 92019, Auckland, New Zealand \\ *Corresponding author, e-mail: xilai-li@163.com
}

(C) Science Press and Institute of Mountain Hazards and Environment, CAS and Springer-Verlag Berlin Heidelberg 2013

\begin{abstract}
In many ecosystems ungulates have coexisted with grasslands over long periods of time. However, high densities of grazing animals may change the floristic and structural characteristics of vegetation, reduce biodiversity, and increase soil erosion, potentially triggering abrupt and rapid changes in ecosystem condition. Alternate stable state theory provides a framework for understanding this type of dynamic. In the Sanjiangyuan atop the Qinghai-Tibetan plateau (QTP), grassland degradation has been accompanied by irruptions of native burrowing animals, which has accentuated the loss of ground cover. Severely degraded areas of alpine meadows are referred to as 'Heitutan'. Here, using the framework of alternate stable state theory, we describe the proximate and ultimate drivers of the formation of Heitutan on the QTP, and we assess prospects for recovery, in relation to the degree of biophysical alteration, of these alpine meadows. Effective rehabilitation measures must address the underlying causes of degradation rather than their symptoms. Heitutan degradation is not uni-causal. Rather it reflects different mechanisms operating at different spatio-temporal scales across this vast region. Underlying causes include overly aggressive exploitation of the grasslands (e.g. overgrazing), amplification of grazing and erosion damage by small mammals when outbreaks occur, and/or climate change. Given marked variability in environmental conditions and stressors, restorative efforts must vary across the region. Restoration efforts are likely to
\end{abstract}

Received: 24 October 2012

Accepted: 6 July 2013 yield greatest success if moderately and severely degraded areas are targeted as the first priority in management programmes, before these areas are transformed into extreme Heitutan.

Keywords: Heitutan degraded grassland; Alpine meadow; Restoration/rehabilitation; Sanjiangyuan; Qinghai-Tibet Plateau (QTP)

\section{Introduction}

Environmental damage resulting from population pressure, intensifying land-use and climate change, alongside many other factors, has been accompanied by a progressive depletion of natural resources. The Global Assessment of Human-Induced Soil Degradation concluded that "approximately $23 \%$ of the world's used terrestrial area was degraded: $38 \%$ was lightly degraded; $46 \%$ moderately degraded; and $16 \%$ strongly to extremely degraded" (Oldeman and van Lynden 1997). Grazing lands are possibly "the most degraded land use type in the world" (Papanastasis 2009), and grassland degradation is a world-wide problem (Kessler and Laban 1994; Muller et al. 1998; Carrick and Krüger 2007).

Grassland refers to expansive and mostly unimproved land that supports natural vegetation such as grasses or grass-like plants, including forbs and shrubs (Li et al. 2013). Grassland, rangeland 
and pasture are loosely synonymous terms used in different parts of the world to refer to a similar set of environmental conditions where ecosystems produce forage (Ren 2000). In this paper we use the term 'grassland' throughout. Grassland degradation is characterised by reduced productivity, fragmentation of grass cover, reduction in soil fertility, soil compaction, an increase in unpalatable grass species, or a combination of some or all of these factors ( $\mathrm{Li}$ 1997). As grassland ecosystems provide a wide range of ecological goods and services, including animal habitat, soil-related services, grazing resources for livestock and carbon storage (White et al. 2000; Lund 2007; Wen et al. 2013), degradation affects the livelihood of the pastoralists who depend on them (Harris 2010). White et al. (2000) suggest that the extent and severity of soil degradation in grassland areas has increased markedly in recent decades.

In many ecosystems ungulates have coexisted with grasslands over long periods of time. However, the viability of some of these ecosystems is threatened by recent changes in stocking rates arising from domestication programmes. High densities of grazing animals may alter the floristic and structural characteristics of vegetation, reduce biodiversity, and increase soil erosion. Hence, humans can affect the condition of grassland ecosystems through modification of the grazing regime. The impacts of domestic animals may be either positive or negative, reflecting different stocking densities and behaviours (Sankey et al. 2009). A comparison of the grazing of grasslands by wild ungulates and domestic livestock underlines important transformations in grassland ecosystems. The primary goal of domestic animal husbandry is to maximise animal biomass. Oesterheld et al. (1992) found that, after controlling for primary productivity, the biomass of domestic animals can be up to an order of magnitude higher than that of wild grazers. At high densities, domestic grazing animals can change vegetation composition and structure, reduce biodiversity, and increase soil erosion; in extreme situations, grazing may eliminate much vegetation cover (Evans 1998). Paradoxically, at (appropriately) high densities wild animals can have a positive impact on ecosystem structure and function, but domestic animals appear to have the opposite effect. Thus, the extent to which changes in grazing pressure lead to changes in ecosystem condition does not solely depend on the number (biomass) of livestock, but also on the pattern of their grazing (Oesterheld et al. 1992).

In this paper we describe the proximate and ultimate drivers of the formation of grassland degradation on the Qinghai-Tibet Plateau (QTP) in western China. We appraise prospects for recovery in relation to the degree of biophysical alteration of these alpine meadows. We place these long-term spatio-temporal dynamics in the context of current interest in the dynamics and restoration of ecological systems showing alternative stable states. Better understanding of regional variability in drivers of grassland degradation can contribute to protection and management of these fragile alpine ecosystems.

\section{Cause of Grassland Degradation in the Sanjiangyuan}

\subsection{Grassland resources and degradation in China}

Most of China's rich grassland resources are distributed in the west and northwest, in environmental settings that include alpine meadow, tundra and steppe. Collectively, these rangelands cover $41.7 \%$ (400 million ha) of China's land area (Ren et al. 2008). The QTP is a vast, elevated plateau in western China, bordering India in the west, and the Kunlun, Arjin and Qilian Mountains in the northeast and northwest. The Sanjiangyuan lies at the heart of the QTP in the southern part of Qinghai province (latitude $31^{\circ} 39^{\prime}-36^{\circ} 12^{\prime} \mathrm{N}$, longitude $89^{\circ} 45^{\prime}-102^{\circ} 23^{\prime} \mathrm{E}$; Li et al. 2012a).

Humans have used alpine meadows dominated by Kobresia spp. (Cyperaceae) for livestock grazing for more than 8,000 years (Kaiser et al. 2008; Miehe et al. 2008, 2009). Prior to the mid-Holocene climatic optimum, landscapes of the QTP were more heavily forested but were then cleared (largely by fire) and Kobresia subsequently became established. If grazing pressures are removed, Kobresia pastures disappear. The alpine ecosystems in the region are locally threatened by increases in human population and uncontrolled production activities ( $\mathrm{Ma}$ et al. 2000; $\mathrm{Du}$ et al. 2004; Zhou et al. 2005; $c f$., Harris 2010; Li et al. 
2013). Removal of vegetation has reduced the water-retention capacity of the region and lowered the capacity of the environment to cope and recover in periods of stress (Li 2007). Today, between $26-46 \%$ of the total grassland area in the
Sanjiangyuan can be considered to be degraded (Fan et al. 2010).

Areas of degraded alpine meadows on the QTP are referred to as 'Heitutan' (see Figure 1; Li et al. 2012b). Increased proportions of bare

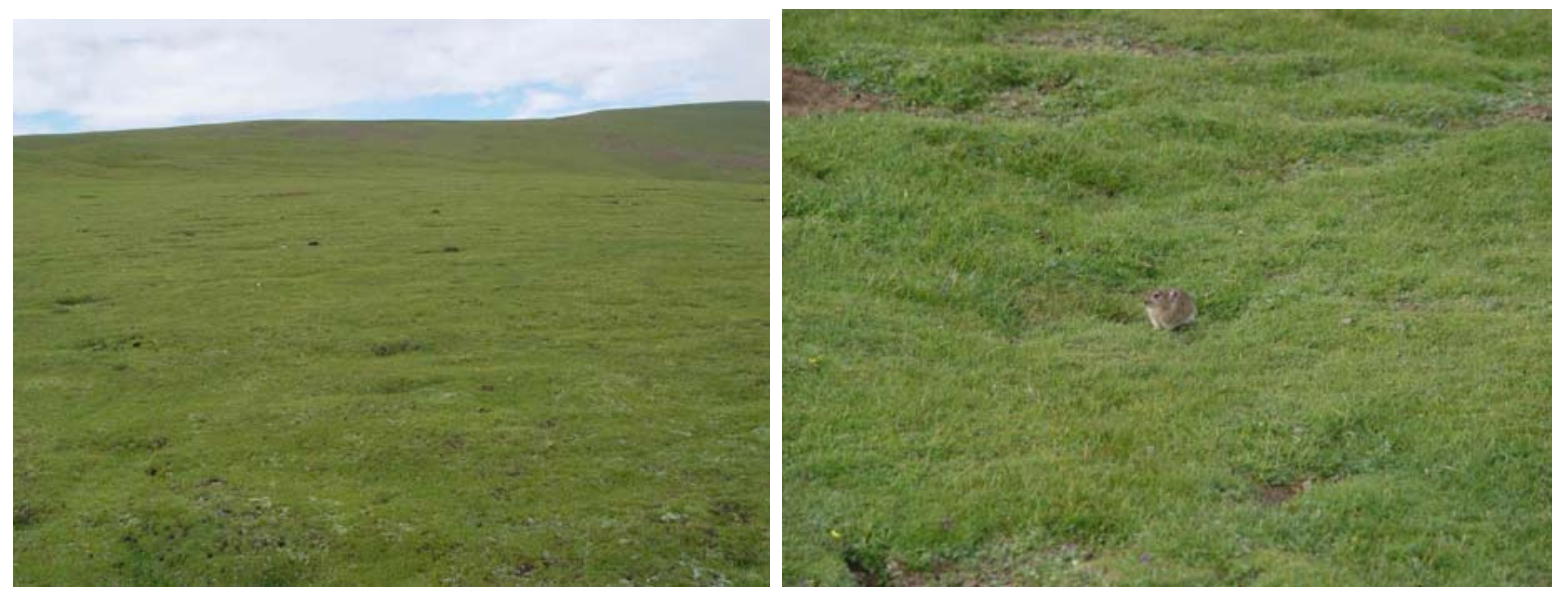

(a) Alpine meadow: high density Kobresia populations are highly resilient
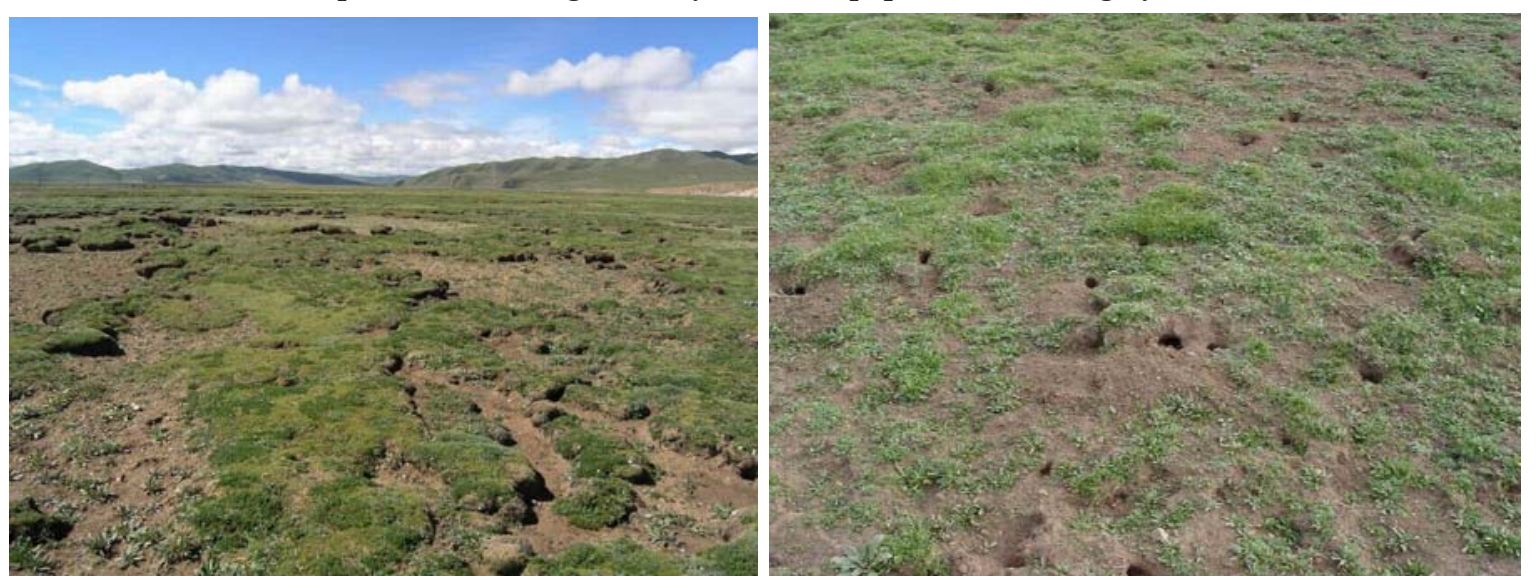

(b) Severely degraded Heitutan: severe small mammal damage and soil erosion extend across around $40 \%$ of the area covered by alpine meadow
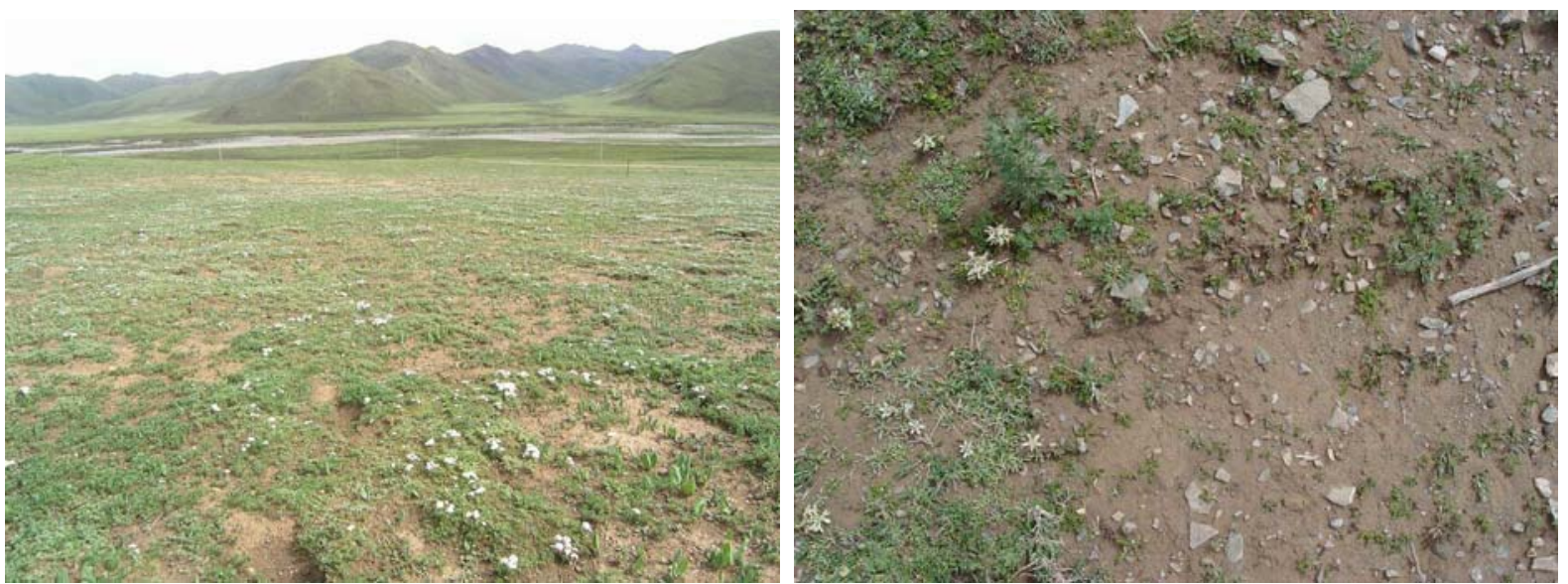

Figure 1 Various stages and states of Heitutan formation from (a) intact through (b) severely degraded to (c) extremely degraded in the Sanjiangyuan (photos: Li Xi-lai 2007). Figures on the right show a close view of grassland conditions in each condition. 
ground/eroded ground, less palatable herbage and more unpalatable plant species in these areas have accelerated rates of water and soil erosion. Nearly $14 \%\left(49,000 \mathrm{~km}^{2}\right)$ of the Sanjiangyuan has been degraded to Heitutan grassland (Li et al. 2013). Given their black colour and geographic location, these areas have been variously referred to as 'black soil patch', 'black beach', 'black soil beach', 'black slope', 'black mountain' (Li 2002; Li et al. 2013; Miehe et al. 2008), 'black soil-type degraded grassland' (Ma et al. 1999), 'black soil type grassland' (Zhou et al. 2005) and 'black soil land' (Shang et al. 2008).

\subsection{Drivers of Heitutan formation in the Sanjiangyuan}

Given the climatic setting, wind erosion, water erosion and freeze-thaw processes are prevalent across the Sanjiangyuan, and eroded areas extend over some $26 \%\left(95,000 \mathrm{~km}^{2}\right)$ of the region (Chen et al. 2007). Intensified soil erosion, along with frequent droughts and flood conditions, seriously restrict prospects for industrial and agricultural development, and threatens the ecosystems of the area. Small mammal population irruptions may also intensify deterioration of these grassland ecological environments (although the causality of these interactions is uncertain). Expansion of areas of degraded ground enhances water and wind erosion in a positive feedback cycle, with negative impacts on grassland plant and soil assemblages (Liu et al. 1999; Zhou et al. 2005). Surviving areas of alpine meadow are being transformed into degraded ground and eventually into Heitutan (Zhou et al. 2005).

Grassland degradation on the QTP is manifest in diverse forms that include Heitutan degradation of alpine meadow ( $\mathrm{Li}$ 2002), desertification of alpine-steppe (Liu et al. 1999), and the increasing dominance of unpalatable species (e.g. Stellera chamaejasme Thymelaeaceae and Oxytropis kansuensis Fabaceae) in temperate mountain meadows (Li et al. 2013). Under appropriate grazing regimes, alpine meadows support a reasonable density of grazing animals with little apparent degradation (Miehe et al. 2008, 2009). During grassland degradation, remnant areas of alpine meadow dominated by Cyperaceae (especially genus Kobresia) are transformed into degraded ground and subsequently Heitutan. Over time, the loss of vegetation, possibly amplified by small mammal activity, can negatively impact grasslands and promote a regime shift towards Heitutan (Shang et al. 2006; Li et al. 2013). In areas of Heitutan, the loss of palatable forage species, coupled with increasing bare ground and the amplifying affects of small mammals, can result in accelerated rates of water and soil erosion, potentially accelerating, if not necessarily triggering, the degradation of these grassland environments (Liu et al. 1999; Zhou et al. 2005). Because small mammals are favoured by degradation, their presence at high densities is an indicator of vegetation loss and their activities may worsen existing conditions (Arthur et al. 2007; Harris 2010; Pech et al. 2007). Soil erosion impacts upon the soil hydrology regime, furthering the impacts of grassland degradation in these dryland settings.

Proximate and ultimate causes of Heitutan formation on the QTP include anthropogenic, ecological and climatic drivers. It is important to emphasise that these drivers vary in their importance in space and time, and interact across a range of spatio-temporal scales. Hence, it is not helpful to think of grassland degradation on the QTP monistically and it is probably not possible to disentangle these different effects (for example, the effects of human activity may be amplified by climate change).

\subsection{Anthropogenic drivers}

Grasslands in China have been grazed for millennia without notable degradation until recent years (Li 1997). Degradation has emerged as a problem over the last five decades, coincident with increasing human disturbance (Xiang et al. 2009), with the area considered to be 'degraded' growing at $1.9 \%$ per annum over the period 1980-1995 (Li 1997). The fact that grassland degradation coincides with rapid population growth suggests that direct and local anthropogenic factors play at least as important a role in driving degradation as do broad-scale factors such as climate change (e.g. Zhou et al. 2005). This claim is supported by the fact that since the 1980 s grassland degradation in Maduo has worsened despite more favourable conditions (higher temperature and rainfall) for 
grass growth (Bai et al. 2002).

Historic grazing data for the Sanjiangyuan suggests that grazing occurred at a low intensity (less than 20\% of stocking rate) until around 1900 (see Figure 2). From 1900 to 1949, average grazing intensity increased to around $20-40 \%$, and anecdotal evidence suggests that degradation occurred only where grazing was locally intense (Jing and $\mathrm{Xu}$ 2005). Field-based investigations suggest that grassland degradation in the Sanjiangyuan began in and around residential areas and areas used for feeding and watering livestock, before progressing into winter pasture and finally high elevation summer pasture (Jing and $\mathrm{Xu}$ 2005). The fact that the level of degradation is negatively correlated with distance from settlements within 4-12 km, and negatively correlated with elevation (Liu et al. 2006) suggests that high and relatively remote grassland is grazed less frequently than lower and more easily accessible rangeland ( $\mathrm{Li}$ et al. 2013). The majority of grassland degradation in the Sanjiangyuan has occurred since 1960 (Jing et al. 2006). From 1950 to 1966 the grassland had a grazing intensity around $40-60 \%$; at the same time the pastoral population and livestock numbers increased and small mammal outbreaks also occurred in the stock gathering areas (Yang and Jiang 2002).

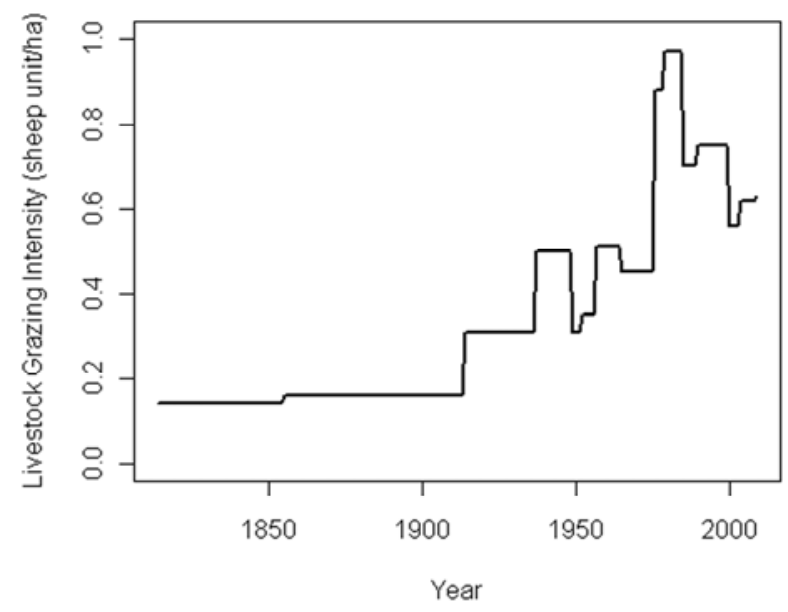

Figure 2 Livestock number dynamics from 1814 to 2009 in the Sanjiangyuan (Guoluo and Yushu prefectures only).

Data source: livestock numbers from Jing and $\mathrm{Xu}$ (2005) and Fan et al. (2010) before 2000 and Qinghai Statistic Bureau after 2000, grassland area from Chen et al. (2007). An adult sheep is assumed to be equivalent to one sheep unit, one adult yak is equivalent to four sheep units.
Interestingly, degradation has continued from 1980 to the present, even though the grazing intensity (number of livestock per unit area) has somewhat declined (Li et al. 2013).

Tane (2011) describes the range of negative effects of domestic livestock herds upon the region's soils (e.g. compaction and erosion) and hydrology (e.g. reduced rainfall recharge). These processes rapidly dry out the yak herds' favored camping and grazing grounds leaving them depleted, and sparsely covered in short pasture grasses and unpalatable species. Such localised areas provide ideal habitat for the small mammals that burrow in the depressions formed by the yaks' trampling. When yak grazing is either continuous or combined with grazing by sheep and horses, the unavoidable outcomes are the widespread depletion of surface turf/sod or wetlands, the proliferation of short pasture dominated by sedges (e.g. Kobresia; see Zhao et al. 2006), the disabling of aquifers, and, eventually, a shift to a degraded Heitutan landscape. These ecological conditions greatly expand habitats capable of supporting high populations of small mammals, which in turn aggravate the natural resource problems further.

In summary, many areas of alpine meadow have become extremely degraded as the vegetation community structure has been altered and soil fertility depleted (Zhou et al. 2005). A vicious circle has been generated, characterised by overgrazing $\rightarrow$ vegetation degradation $\rightarrow$ harm by small mammals when outbreak occurs $\rightarrow$ grassland degradation $\rightarrow$ and so forth. The catalyst for this cycle is overgrazing, and its intensification is the result of mismatches between the goals of local pastoralism and landscape-level management in these grasslands ( $\mathrm{Li}$ 2002).

\section{4 'Small mammal' population outbreaks}

The plateau pika (Ochotona curzoniae), plateau zokor (Myospalax baileyi), plateau vole (Pitymys irene), Brandt's vole (Micotus brandti) and Himalayan marmots (Marmota himalayana) are collectively referred to as 'small mammals' of the QTP. Grasslands can be severely impacted by their burrowing and gnawing behaviour when outbreaks (population irruptions) of these small mammals occur (Zhou et al. 2005). The mammals' activities accelerate erosion and degradation rates by 
loosening turf and sod and by elevating plant root mortality (Limbach et al. 2000; Zhou et al. 2005). Outbreaks of these burrowing animals in the Sanjiangyuan affected an area of 6.4 million ha in 2005 (Chen et al. 2007) - around 17\% of the region. In some localities more than $30 \%$ of the area has high density mammal populations (up to 450 individuals or 4,500 burrows.ha-1) (Miehe et al. 2008). These values greatly exceed the sustainable threshold of $c$. 64 burrows per hectare suggested by field investigations (Yang and Jiang 2002).

The rapid rise in the population of native small mammals on the QTP over the past 40 years reflects alterations to the structure of the food chain induced by illegal hunting and inappropriate control measures (e.g. over-utilization of poisons; Pech et al. 2007). These practices have, in turn, reduced the beneficial role of eagles (Accipiter spp.), Tibetan fox (Vulpes ferrilata) and weasels (Mustelea spp.) in limiting the impacts of small mammals (Zhou et al. 2005). These and other factors have contributed to plagues of small mammals over the last four decades (Li et al. 2013).

The role of burrowing mammals in the degradation process remains contentious (e.g. see Pech et al. 2007; Harris 2010). Although there is a strong associative relationship between grazing intensity and the frequency of small mammal population outbreaks (Figure 3), this is not necessarily causal. As grazing levels on the QTP have increased over the twentieth century, so too

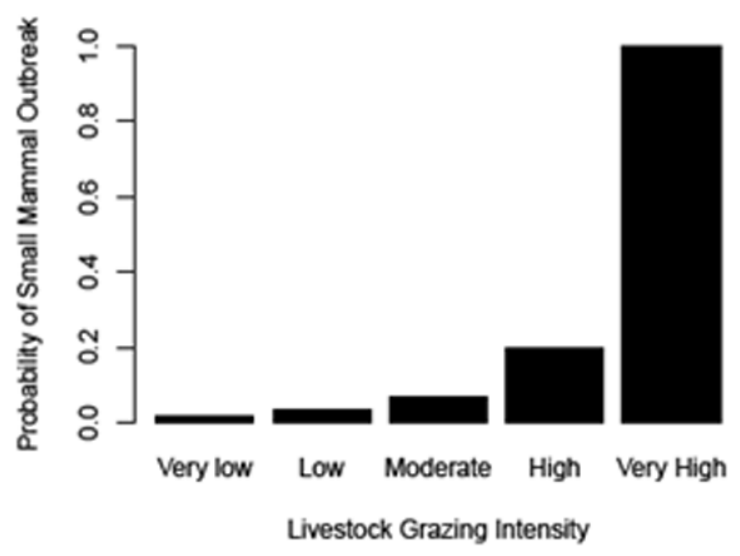

Figure 3 Livestock grazing intensity and the frequency of small mammal outbreaks (Li 2012). Five different grazing levels are very low $(<20 \%$ of stocking rate), low ( $<40 \%$ of stocking rate), moderate $(<60 \%$ of stocking rate), high ( $<80 \%$ of stocking rate) and very high grazing levels ( $\geq 80 \%$ of stocking rate). The probability of small mammal outbreak increases dramatically with livestock grazing intensity. have the frequency of small mammal population irruptions and the extent of Heitutan. At one level species such as plateau pika are critical ecosystem engineers (see Smith and Foggin 1999): for example, their foraging and burrowing activities are beneficial in recycling soil nutrients, and they are an important prey species for a suite of predators. However, other researchers consider irruptions of these species to be harmful triggers of soil erosion (Zhou et al. 2005; Chen et al. 2007). Burrowing activities and impacts upon ground cover may accelerate grassland degradation (Fan et al. 1999; Arthur et al. 2007). In the process of digging burrows, pikas pile the loose soil around and over healthy grassland, suffocating vegetation and supplying the source material for soil erosion. In the absence of physical destruction by small mammals, alpine meadow suffers minimal erosion because of the resistant, hard sod. Population irruptions of small mammals have increased in frequency since 1970 from once every 7 years to once every 3 to 5 years (Zhang et al. 2003). As a result, poisoning programs have been used to control these small mammals since 1958, but the efficacy of these programs is uncertain (Pech et al. 2007). Long-term biological methods, such as reducing domestic grazing intensity or rehabilitating the vegetation of degraded grassland, present an alternative approach.

\subsection{Climate change}

The warming of the regional climate over the last 40 years in the Sanjiangyuan is not disputed (Li et al. 2006; Chen et al. 2007), with a significant increase in average annual temperature over the period 1961 to 2004 (Li et al. 2006). Mean annual temperature in 2003 was the highest on record, $1.4^{\circ} \mathrm{C}$ higher than the average across the previous 30 years. As temperature adjustments are most marked in autumn and winter, the annual variation in temperature has also decreased (Li et al. 2006; Chen et al. 2007). Mean annual precipitation in the Sanjiangyuan from 1961 to 2004 decreased slightly. Seasonal changes in rainfall have varied across the region (Chen et al. 2007). Mean annual evaporation in the Sanjiangyuan increased slightly from 1961 to 2004, with an average increase of 0.13 $\mathrm{mm}$. $\mathrm{yr}^{-1}$ (Chen et al. 2007).

Warming conditions on the QTP have caused a 
notable reduction in the area of snowy mountains and the loss of previously frozen land (Chen et al. 2007). Meadow vegetation seems to be more competitive under warmer conditions than do other steppe species. Results of experimental analyses suggested that warming on the QTP caused a $26 \%-$ $36 \%$ decrease in species richness (Klein et al. 2004) and decreased total aboveground net primary productivity by $40 \mathrm{~g} \cdot \mathrm{m}^{-2} \cdot \mathrm{yr}^{-1}$ in meadow habitats (Klein et al. 2007). The effects of climate change are difficult to predict and may be counter-intuitive. For example, Yu et al. (2010) reported that warmer conditions on the QTP could (paradoxically) result in a shorter growing season, in particular for steppe vegetation, due to failed dormancy breaking mechanisms. Grassland species may adjust to the warming in unexpected ways, potentially resulting in the formation of novel (no analogue) plant communities. Piao et al. (2006) and Klein et al. (2007) have reported that warming may harm vegetation growth in the grasslands, while others (e.g. Zhang and Welker 1996; Du et al. 2004) have speculated that "climate warming may promote vegetation growth on the QTP” (Du et al. 2004: 245). Dong et al. (2011) concluded that climate change and climate variability were driving pastoral ecosystems towards more vulnerable conditions. Work elsewhere indicates that climate change is impacting upon pika numbers and behaviour in unpredictable ways (Beever and Wilkening 2011).

Given these uncertainties in understandings of controls upon the formation and expansion of
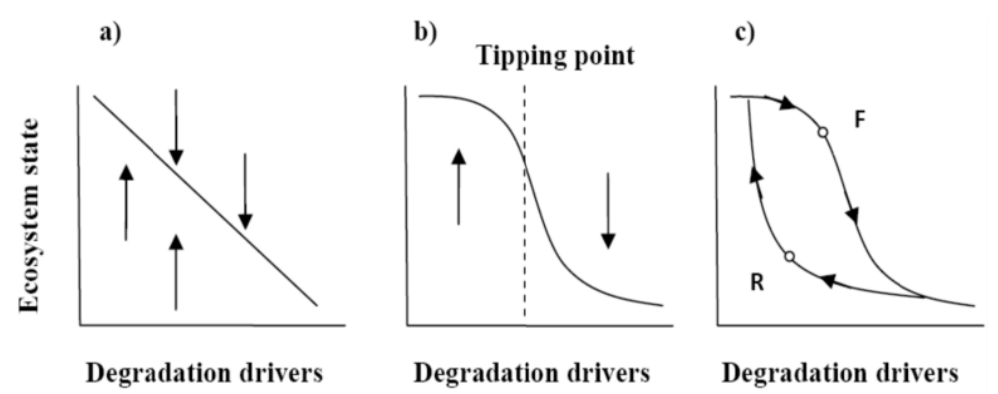

Figure 4 Ecosystem responses to changes in driving conditions can be linear (or smooth) as in (a), even if responses to different drivers may vary, but there is increasing evidence that in some ecosystems responses are nonlinear and abrupt around critical 'tipping points' (as in b). Systems showing abrupt changes may occupy alternate stable states under the same environmental conditions, with each alternate state maintained by strong stabilising feedbacks. Systems showing abrupt changes may also show hysteresis effects where the tipping point to go from condition A to condition $\mathrm{B}$ (a forward shift $[\mathrm{F}]$ ) is not the same as that to return from B to A (a reverse shift $[R])$. Such hysteresis effects pose challenges for ecosystem restoration. Figure after Scheffer et al. (2001).
Heitutan in the Sanjiangyuan, caution must be applied in framing management responses. These considerations should build upon appropriate conceptual framings.

\section{Conceptual Considerations in Assessment of Grassland Degradation}

Ideas stemming from alternate stable state theory have been applied to grassland ecosystems (Van de Koppel et al. 1997; Bestelmeyer 2006; Hobbs and Cramer 2008). Alternate stable state theory holds that under the same environmental conditions ecosystems can be in very different states, with these states being maintained by strong stabilising feedbacks (Scheffer et al. 2001). The iconic ecological example of this type of dynamics is the distribution of forest and savanna in the dominates, and, in places, there are abrupt boundaries between the two ecosystems, likely maintained by complex fire-vegetation feedbacks (Murphy and Bowman 2012).

Shifts between alternate states can be abrupt in both time and space (Scheffer et al. 2001; see Figure 4b), often driven by cascading feedback effects (Hughes et al. 2013). Didham et al. (2005) outline a series of arguments to suggest that alternate stable state dynamics are likely to be more prevalent in systems characterised by strong abiotic gradients and can trait underdispersion. Such shifts between alternate stable states are well documented in grazing systems. Changes in grazing pressure can result in shifts in ecosystem composition with flow-on effects to soils and biogeochemical processes (Schlesinger et al. 1990), and ultimately major, and hard to reverse, shifts in ecosystem state (van de Koppel et al. 1997; Rietkerk and van de Koppel 1997).

One framework that may be able to help diagnose state 
changes in in grassland ecosystems is the 'state and transition model' (Laycock 1991) which conceptualises ecosystems as comprising identifiable states with various processes (such as changes in grazing regime) driving transitions between them. Li et al. (2012b) show that the deterioration of alpine meadow to Heitutan occurs along a continuum with different stages of the degradation process intergrading into each other. Empirical observation of the degradation of the QTP indicates that abiotic and biotic changes can result in different trajectories of change in these alpine grasslands. A state and transition model (as outlined in Figure 5) may be an appropriate framework for understanding the complex, multi-scalar dynamics of degradation on the QTP and helping to identify the alternative trajectories these alpine ecosystems may take in the face of perturbation, and the conditions under which they may arise.

An important implication of alternate stable state models is that the individual states are stabilised by strong feedback processes and are resistant to change (Suding et al. 2004). On the

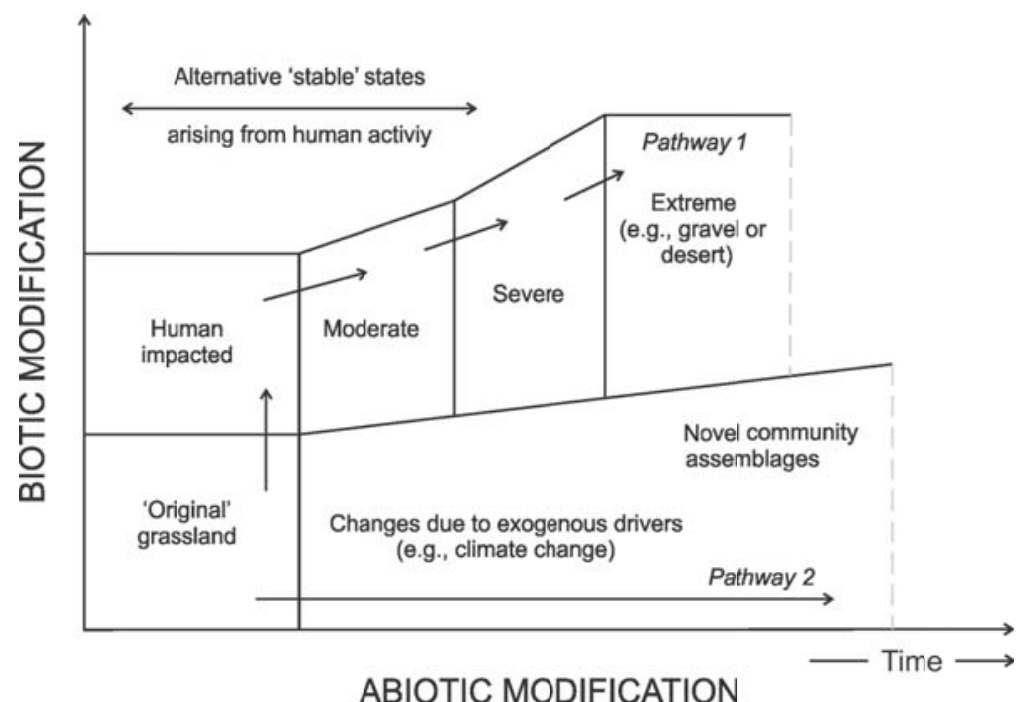

Figure 5 The degradation process and severity of grassland on the QTP under varying levels of biotic and abiotic modification (modified from $\mathrm{Li}$ et al. 2013). Transitions between alternative stable states depend on the extent of anthropogenic and climate influence. Arrows represent possible degradation trajectories. The length of the solid lines represents the time over which degradation processes occur. Note that the location of the transition boundaries in the state space and the length of time required to move between them will vary in space and time, and is not rigidly fixed. The process of grassland degradation via pathway 1 (short-term) is more rapid then that via pathway 2 (long-term). The restoration process aims to reverse the direction of arrows on this diagram. Likelihood of reversal is limited from extreme to severe conditions. However, prospects for recovery are much greater if adjustments from the original or human-modified state are relatively slight.
QTP plateau the Kobresia pastures have remained in the face of moderate grazing pressure corollary is that having achieved this new stable management efforts to move it back to other desirable states (Suding et al. 2004).

\section{Implications for Rehabilitation of Heitutan Degraded Grassland}

As noted by Suding et al. (2004) and Hobbs and Cramer (2008), for restoration programmes to causes and processes of degradation (rather than the symptoms) and (ii) be grounded in an understanding of the feedbacks and constraints operating in the degraded system. In their recent review of restoration ecology, Hobbs and Cramer (2008: 42) state that: "Deciding on what type of intervention, if any, is required for the effective restoration of an ecosystem (or particular components or processes) presupposes a clear understanding of how the ecosystem works and what the outcomes of the intervention are likely to be". Approaches to restoration of degraded grasslands on the QTP have included abiotic, biotic and self-sustainable approaches. Li et al. (2013) argue, however, that rehabilitation is beyond the capacity of individual farmers on the QTP, especially given the potential for hysteresis 
effects in the degradation process, yet traditional engineering-based measures can only 'fix' a limited proportion of affected areas. In this context there is clearly a need to develop a fundamental understanding of these systems such that leverage points' - conditions where active restoration and/or intervention are most likely to be effective can be identified and targeted (Hobbs et al. 2011).

Identifying and quantifying ecological thresholds (as per Li et al. 2012b; Figures 4 (b, c)) and the timeframes of Heitutan degradation processes will aid determination of appropriate land management practices which will, in turn, help to guide effective ecosystem management. Previous research suggests that restoration of the most extreme forms of Heitutan is difficult and slow ( $\mathrm{Li}$ et al. 2013), especially on steep slopes ( $\mathrm{Li}$ et al. 2010a). It is especially difficult to restore the sod in areas dominated by degraded ground and associated soil erosion, because the dominant Cyperaceae species (Kobresia spp.; see Zhao et al. 2006) are slow growing (Li et al. 2010b). Given the challenges faced in efforts to restore Heitutan, management efforts may be best served by targeting areas of moderate degradation, promoting recovery mechanisms that reduce the risk that such areas will be transformed into more degraded Heitutan (Figure 5). Suggested rehabilitation and restoration strategies include less intensive grazing (Fan et al. 2010), efforts to restore edible plants and retain community competition, and measures aimed at protecting remaining soil resources from further depletion $(\mathrm{Li}$ 2002; Shang et al. 2006).

We contend that rehabilitation of Heitutan degraded grassland can benefit from the concepts of state and transition framework (Figure 5). Conceptual frameworks such as state and transition models (Figure 4) can help us predict (at least qualitatively) the conditions under which ecosystem shifts may occur and the likely trajectories of future change (Suding et al. 2004). Heitutan rangeland degradation on the QTP involves multiple constraints and takes multiple trajectories. Intuitively, restoration of rangeland disturbed by human activities is likely easiest to achieve where abiotic conditions have not been modified to a critical degree. On the other hand, for extremely degraded rangeland, drastic human intervention measures are required to combat the constraints, since abiotic conditions have been modified excessively. In those degraded rangelands, cultivated seeding and introduction of pioneering species are needed to lessen abiotic constraints ( $\mathrm{Li}$ 1996). Although some unpalatable species may not be valuable economically, they can assist the restoration of the degraded ecosystem.

\subsection{Programmes to restore extreme Heitutan on beach areas}

The establishment of cultivated grassland may be suitable for the restoration of extremely degraded Heitutan on shallow slopes (a landscape type which covers c. $2.3 \%$ of the Sanjiangyuan; Ma et al. 2008). In such settings, which have very poor soil nutrition and relatively flat slopes, plowing land by machines is feasible due to the relative low risk of water erosion. In areas of extreme Heitutan, sedge (Kobresia) and grass cover is less than 30\% and degraded ground is widespread (Figure 1). Because abiotic physical destruction is intensified with increasing degradation, this 'extreme Heitutan' is difficult to restore (Figure 4c). In such areas, traditional agricultural skills have been applied to enhance the rate of recovery. Fencing-off areas of extremely degraded grassland and long-term control of grazing (Feng et al. 2003; Kaiser et al. 2008), along with treatment of suitable grass seeds (e.g. pelleting, Liu et al. 2010) and the planting of native species (e.g. Kobresia spp.) are required to restore these Heitutan grasslands (Zhou et al., 2005). Engineering measures may be required to limit soil erosion and improve soil properties. In some instances the use of inedible/weed plants as pioneer plants may also be necessary ( $\mathrm{Li}$ et al. 2013). Restoration of these areas is likely to take many decades or even centuries; the greater the degree of degradation, the higher - in both time and money - the cost of repair. Hence, targeted management of less degraded areas may be required to minimise the costs associated with restoration, and to ensure that these areas are not transformed into an extremely degraded condition.

\subsection{Programmes to restore all grades of Heitutan on slope areas}

Fencing/exclosure to support the selfrestoration of grassland is suitable for restoration of 
all grades/classes of Heitutan degraded grasslands on steeper slopes (greater than $7^{\circ}$ ); this type of degradation accounts for around $5 \%$ of the total land area of the Sanjiangyuan (Ma et al. 2008). Such grassland is not suitable to plow using machines due to the greater risk of water erosion. The restoration of this grassland has typically involved the control of small mammal outbreaks, and the fencing of degraded areas for 10 years or more to support the slow self-restoration of the original vegetation (Ma et al. 2007). More interventionist measures can help restore such degraded areas more quickly, such as using agricultural skills for sowing suitable native grass species (e.g. Ma et al. 2007; Shang et al. 2006). Planting of suitable grass pelleted seeds could be prioritised in Heitutan grassland on steeper slopes, and Kobresia plants could be transplanted to support the restoration of original vegetation of alpine meadow (Zhao et al. 2006; Li et al. 2012b). In other degraded environments, the potential for nurse plants to play an important role for seedling establishment via facilitative effects has been demonstrated (Huber-Sannwald and Pyke 2005), and such methods are worth trialling on the QTP. Irrespective of the application of such interventions, restoration in such areas is likely to be slow and expensive and by necessity is initially likely to be highly local. It is also important to note the relative dearth of information regarding the restoration of Heitutan grasslands relative to restoration of grassland elsewhere in the world. Further empirical and model-based research is required to evaluate the potential effectiveness of restoration options.

\section{Conclusions}

The formation of degraded Heitutan grassland in alpine meadows on the QTP threatens the ecological integrity of the region, and negatively impacts local peoples' livelihoods and local industrial and agricultural development. The process of extreme Heitutan formation follows (at least schematically) a pathway of: increasing grazing disturbance $\rightarrow$ triggering high frequency of small mammal outbreak $\rightarrow$

\section{References}

Arthur AD, Pech RP, Jiebu, et al. (2007) Grassland degradation on the Tibetan Plateau: the role of small mammals and increasing burrows abundance of small mammals $\rightarrow$ soil erosion $\rightarrow$ emergence of largely eroded (bare) ground $\rightarrow$... Unsustainably high grazing levels underlie this vicious cycle and the exact role of small mammals remains unclear but is probably context-dependent (beneficial to the grassland ecosystem where there is an appropriate stocking rate but, under overgrazing, it becomes deleterious).

The extent of Heitutan across the Sanjiangyuan emphasises the importance of improved protection of these alpine meadows. Reducing grazing pressure in these systems can prevent Heitutan degradation. Short-term, intensive measures, such as fencing, creation of cultivated grasslands, coupled with relief from grazing and small mammal outbreaks, are required to cope with areas subject to extreme degradation. Targeted management practices should prioritise areas of moderate and severe degradations where prospects for recovery remain realistically achievable over reasonable timeframes. In areas of extreme Heitutan, the following restoration pathway is recommended: rehabilitate largely eroded (bare) ground $\rightarrow$ control small mammal outbreaks (e.g. biological methods) $\rightarrow$ control soil erosion $\rightarrow$ reduce overgrazing disturbance $\rightarrow \ldots$

\section{Acknowledgements}

This research was supported by Special Fund for Agroscientific Research in the Public Interest (201203041), the National Natural Sciences Foundation of China (41161084) and International Science \& Technology Cooperation Program of China, MOST (2011DFG93160, 2011DFA20820). PhD work on this topic by $\mathrm{Li}$ Xilai was undertaken with the support of a Plant Science Scholarship at the University of Auckland. Gary Brierley gratefully acknowledges support from a Visiting Professorship at China Academy of Sciences. The constructive comments of two anonymous reviewers helped to improve this paper.

methods of control. Canberra: Australian Centre for International Agricultural Research Technical Report 67. p 35. 
Bai W, Zhag Y, Xie G, et al. (2002) Analysis of formation causes of grassland degradation in Maduo County in the source region of Yellow River. Chinese Journal of Applied Ecology 13(7): 823-826. (In Chinese)

Beever EA, Wilkening JL (2011) Playing by new rules: altered climates are affecting some pikas dramatically - and rapidly. The Wildlife Professional 5(3): 38-41.

Bestelmeyer BT, Ward JP, Havstad KM (2006) Soil-geomorphic heterogeneity governs patchy vegetation dynamics at an arid ecotone. Ecology 87(4): 963-973. DOI: 10.1890/0012-9658 (2006)87[963:SHGPVD]2.0.CO;2

Carrick PJ, Krüger R (2007) Restoring degraded landscapes in lowland Namaqualand: Lessons from the mining experience and from regional ecological dynamics. Journal of Arid Environments 70(4): 767-781. DOI: 10.1016/j.jaridenv.2006. 08.006

Chen GC, Chen XQ, Gou XJ (2007) Ecological Environment in Sanjiangyuan Natural Reserve. Qinghai People's Press, Xining, China. (In Chinese)

Didham RK, Watts CH, Norton DA (2005) Are systems with strong underlying abiotic regimes more likely to exhibit alternative stable states? Oikos 110: 409-416. DOI: 10.1111/ j.0030-1299.2005.13883.x

Dong S, Wen L, Liu S, et al. (2011) Vulnerability of worldwide pastoralism to global changes and interdisciplinary strategies for sustainable pastoralism. Ecology and Society 16(2): Special section p1.

Du M, Kawashima S, Yonemura S, et al. (2004) Mutual influence between human activities and climate change in the Tibetan Plateau during recent years. Global and Planetary Change 41: 241-249. DOI: 10.1016/j.gloplacha.2004.01.010

Evans R (1998) The erosional impacts of grazing animals. Progress in Physical Geography 22(2): 251-268.

Fan JW, Shao QQ, Liu JY, et al. (2010) Assessment of effects of climate change and grazing activity on grassland yield in the Three Rivers Headwaters Region of Qinghai-Tibet Plateau, China. Environmental Monitoring and Assessment 170(1): 571-584.

Fan NC, Zhou WY, Wei WH, et al. (1999) Rodent pest management in Qinghai-Tibet alpine meadow ecosystem. In: Singleton G, Hinds L, Leirs H, Zhang Z (eds.), Ecologicallybased management of rodent pests. pp 285-304. Australian Centre for International Agricultural Research, Canberra, Australia.

Feng M, Yang, Deng Y, et al. (2003) Grassland rehabilitation and social development in the low mountain area of the Jinsha River Valley, China. Mountain Research and Development 23(2): 124-127. DOI:10.1659/o276-4741(2003) 023[0124:GRASDI]2.0.CO;2

Harris RB (2010) Rangeland degradation on the QinghaiTibetan plateau: A review of the evidence of its magnitude and causes. Journal of Arid Environments 74(1): 1-12. DOI: 10.1016/j.jaridenv.2009.06.014

Hobbs RJ, Cramer VA (2008) Restoration ecology: Interventionist approaches for restoring and maintaining ecosystem function in the face of rapid environmental change. Annual Review of Environment and Resources 33: 39-61. DOI 10.1146/annurev.environ.33.020107.113631

Hobbs RJ, Hallett LM, Ehrlich PR, et al. (2011) Intervention ecology: applying ecological science in the twenty-first century. BioScience 61: 442-450.

Huber-Sannwald E, Pyke DA (2005) Establishing native grasses in a big sagebrush-dominated site: An intermediate restoration step. Restoration Ecology 13(2): 292-301. DOI: 10.1111/j.1526-100X.2005.00037.x

Hughes TP, Linares C, Dakos V, et al. (2013) Living dangerously on borrowed time during slow, unrecognized regime shifts. Trends in Ecology \& Evolution 28: 149-155. DOI: 10.1016/ j.tree.2012.08.022

Jing H, Xu JL (2005) The affect of human economic activity, from on mid-Qing dynasty, on the eco-environment of three rivers source regions. Ascent 24(3): 75-92.

Jing ZC, Wang QJ, Shi HL, et al. (2006) The poison effect experiment of Botulin model D for plateau pikas (Ochotona curzoniae). Pratacultural Science 23: 89-91. (In Chinese)

Kaiser K, Miehe G, Barthelmes A, et al. (2008) Turf-bearing topsoils on the central Tibetan Plateau, China: Pedology, botany, geochronology. Catena 73(3): 300-311. DOI: 10.1016/ j.catena.2007.12.001

Kessler JJ, Laban P (1994) Planning strategies and funding modalities for land rehabilitation. Land Degradation \& Development 5(1): 25-32. DOI: $10.1002 / \mathrm{ldr} .3400050104$

Klein JA, Harte J, Zhao XQ (2004) Experimental warming causes large and rapid species loss, dampened by simulated grazing, on the Tibetan Plateau. Ecology Letters 7(12): 11701179. DOI: 10.1111/j.1461-0248.2004.00677.x

Klein JA, Harte J, Zhao XQ (2007) Experimental warming, not grazing, decreases rangeland quality on the Tibetan Plateau. Ecological Applications, 17(2): 541-557. DOI: 10.1890/05-0685

Laycock WA (1991) Stable states and thresholds of range condition on North American rangelands: a viewpoint. Journal of Range Management 44: 427-433. DOI: 10.2307/ 4002738

Lehmann CER, Archibald SA, Hoffmann WA, et al. (2011) Deciphering the distribution of the savanna biome. New Phytologist 191:197-209. DOI:10.1111/j.1469-8137.2011.03689.x

Li B (1997) The rangeland degradation in North China and its preventive strategy. Scientia Agricultura Sinica 30(6): 1-9. (In Chinese)

Li K (2007) A protection proposal of water conservancy engineering on fish production and hydrophily living things. China Fish 12: 72-73. (In Chinese)

Li L, Li F, Guo A, et al. (2006) Study on the climate change trend and its catastrophe over Sanjiangyuan Region in recent 43 years. Journal of Natural Resources 21: 79-85. (In Chinese) $\mathrm{Li}$ XL (2012) The spatio-temporal dynamics of four plantfunctional types (PFTs) in alpine meadow as affected by human disturbance, Sanjiangyuan region, China. PhD thesis, The University of Auckland, New Zealand.

Li XL, Gao J, Brierley G, et al. (2013) Rangeland degradation on the Qinghai-Tibet Plateau: Implications for rehabilitation. Land Degradation and Development 24: 72-80. DOI: $10.1002 / \mathrm{ldr} .1108$

Li XL (2002) Natural factors and formative mechanism of "black sands" formed on grassland in Qinghai-Tibetan plateau. Pratacultural Science Sinica 19(1): 20-22. (In Chinese)

Li XL, Brierley G, Shi DJ, et al. (2012a) Ecological protection and restoration in Sanjiangyuan National Nature Reserve, Qinghai Province, China. In: Higgitt D (Ed.), Perspectives on Environmental Management and Technology in Asian River Basins. pp 93-120. SpringerBriefs in Geography DOI: 10.1007/978-94-007-2330-6_6

Li XL, Li FJ, Huang BN, et al. (1996) A primarily study on biomass and seedling growth of several Kobresia on the Qinghai-Tebetan Plateau. Acta Pratacultural Science 5(4): 4854. (In Chinese)

Li XL, Perry GLW, Brierley G, et al. (2010a) Grassland degradation of alpine meadow in the Sanjiangyuan region. In: Brierley GJ, Li XL, Chen G (eds.), Landscape and Environmental Science and Management in the Sanjiangyuan Region. pp 138-148. Qinghai People's Publishing House, Xining, China.

Li XL, Perry GLW, Brierley G, et al. (2010b) A simulation model of ramet population dynamics of Kobresia humilis on abandoned farmland in alpine meadow on the QinghaiTibetan Plateau. In: Brierley GJ, Li XL, Chen G (eds.), Landscape and Environmental Science and Management in the Sanjiangyuan Region. pp 206-213. Qinghai People's Publishing House, Xining, China.

Li XL, Perry GLW, Brierley G, et al. (2012b) Quantitative assessment of degradation classifications in degraded alpine meadows (Heitutan), Sanjiangyuan, western China. Land Degradation \& Development in press. DOI: 10.1002/ldr.2154

Limbach W, Davis J, Bao T, et al. (2000) The introduction of sustainable development practices of the Qinghai livestock development project. In: Zheng D, Zhu L (eds.), Formation and evolution, environment changes and sustainable development on the Tibetan Plateau. pp 509-522. Academy 
Press, Beijing, China.

Liu L, Zhang Y, Bai W, et al. (2006) Characteristics of grassland degradation and driving forces in the source region of the Yellow River from 1985 to 2000. Journal of Geographical Sciences 16(2): 131-142. DOI: 10.1007/s11442-006-0201-4

Liu W, Wang QJ, Wang X, et al. (1999) Ecological process of forming 'Black-Soil-Type' degraded grassland. Acta Agrestia Sinica 7(4): 300-307.

Lund HG (2007) Accounting for the World's rangelands. Rangelands 29(1): 3-10.

$\mathrm{Ma} \mathrm{H}$ (2007) Explanation about the causes of ecological degradation in the Sanjiangyuan District under the perspectives of new institutional economics. Tibetan Studies 3: 88-96. (In Chinese)

Ma YS, Dong QM, Shi JJ, et al. (2008) Classification and rehabilitating measurements of "black-soil-beach" degraded grassland in Three River Source Region. Chinese Qinghai Journal of Animal and Veterinary Sciences 3: 1-3 (in Chinese)

Ma YS, Lang BN, Shi DJ (2000) Establishing pratacultural system: a strategy for rehabilitation of 'black soil type' deteriorated grassland on the Qinghai-Tibetan Plateau. In: Zheng D, Zhu L (eds.), Formation and evolution, environment changes and sustainable development on the Tibetan Plateau. pp 334-339. Academy Press, Beijing, China. (In Chinese)

Ma YS, Lang BN, Li QY, et al. (1999) The present status of the grassland ecological environment in the headwater and the approaches to resume the deteriorated grassland. Grassland of China 6: 59-61. (In Chinese)

Miehe G, Miehe S, Kaiser K, et al. (2008) Status and dynamics of the Kobresia pygmaea ecosystem on the Tibetan Plateau. AMBIO: A Journal of the Human Environment 37(4): 272-279. DOI: 10.1579/0044-7447(2008)37[272:SADOTK]2.0.CO;2

Miehe G, Miehe S, Kaiser K, et al. (2009) How old is pastoralism in Tibet? An ecological approach to the making of a Tibetan landscape. Palaeogeography, Palaeoclimatology, Palaeoecology 276: 130-147. DOI: 10.1016/j.palaeo.2009.03. 005

Muller S, Dutoit T, Alard D, et al. (1998) Restoration and rehabilitation of species-rich grassland ecosystems in France: a review. Restoration Ecology 6(1): 94-101. DOI: 10.1046/ j.1526-100x.1998.06112.x

Murphy BP, Bowman DMJS (2012) What controls the distribution of tropical forest and savanna? Ecology Letters 15:748-758. DOI: 10.1111/j.1461-0248.2012.01771.x

Oesterheld M, Sala OE, McNaughton SJ (1992) Effect of animal husbandry on herbivore-carrying capacity at a regional scale. Nature 356:234-236.DOI: doi:10.1038/356234ao

Oldeman LR, van Lynden GWJ (1997) Revisiting the GLASOD methodology. In: Lal R, Blum WH, Valentine C, Steward BA (eds.), Methods for Assessment of Soil Degradation. pp 423439. CRC Press, New York, USA.

Papanastasis VP (2009) Restoration of degraded grazing lands through grazing management: Can it work? Restoration Ecology 17(4): 441-445. DOI: 10.1111/j.1526-100X.2009. 00567. $\mathrm{x}$

Pech RP, Arthur AD, Yanming Z, et al. (2007) Population dynamics and responses to management of plateau pikas Ochotona curzoniae. Journal of Applied Ecology 44(3): 615624. DOI: 10.1111/j.1365-2664.2007.01287.x

Piao SL, Fang JY, He JS (2006) Variations in vegetation net primary production in the Qinghai-Xizang Plateau, China, from 1982 to 1999. Climatic Change 74: 253-267. DOI: 10.1007/s10584-005-6339-8

Rietkerk M, van de Koppel j, (1997). Alternate stable states and threshold effects in semi-arid grazing systems. Oikos 79:69-76. DOI: $10.2307 / 3546091$

Ren J (2000) Grassland definition. In: Sun JX (ed.), Grassland Improvement . pp 1-2. China Agricultural Press, Beijing, China. (In Chinese)

Ren JZ, Hu ZZ, Zhao J, et al. (2008) A grassland classification system and its application in China. The Rangeland Journal 3O(2): 199-209. DOI:10.1071/RJo8002

Sankey TT, Sankey JB, Weber KT, et al. (2009) Geospatial assessment of grazing regime shifts and sociopolitical changes in a Mongolian rangeland. Rangeland Ecology \& Management 62(6): 22-530. DOI: 10.2111/.1/REM-D-09-00014.1

Scheffer M, Carpenter S, Fole JA, et al. (2001). Catastrophic shifts in ecosystems. Nature, 413, 591-596. DOI: 10.1038/ 35098000

Schlesinger WH, Reynolds JF, Cunningham GL, et al. (1990). Biological feedbacks in global desertification. Science 247, 1043-1048. DOI: 10.1126/science.247.4946.1043

Shang ZH, Long RJ, Ma YS (2006) Discussion on restoration and rebuilding of 'Black Soil Patch' degraded meadow in the headwater area of Yangtze and Yellow Rivers. Chinese Journal of Grassland 28(1): 69-74. (In Chinese)

Shang ZH, Ma YS, Long RJ, et al. (2008) Effect of fencing, artificial seeding and abandonment on vegetation composition and dynamics of 'black soil land' in the headwaters of the Yangtze and the Yellow Rivers of the Qinghai-Tibetan Plateau. Land Degradation and Development 19(5): 554-563. DOI: $10.1002 / \mathrm{ldr} .861$

Smith AT, Foggin JM (1999) The plateau pika (Ochotona curzoniae) is a keystone species for biodiversity on the Tibetan plateau. Animal Conservation 2(4): 235-240. DOI: 10.1111/j.1469-1795.1999.tbooo69.x

Suding KN, Gross KL, Houseman GR (2004) Alternative states and positive feedbacks in restoration ecology. Trends in Ecology \& Evolution 19(1): 46-53. DOI: 10.1016/j.tree.2003. 10.005

Tane H (2011) The Yellow River watershed in Qinghai's Sanjiangyuan region. In: Gang C, Li XL, Gao J, Brierley GJ (eds.), Wetland Types and Evolution and Rehabilitation in the Sanjiangyuan Region. pp 92-110. Qinghai People's Publishing House, Xining, Qinghai, China.

Van de Koppel J, Rietkerk M, Weissing FJ (1997) Catastrophic vegetation shifts and soil degradation in terrestrial grazing systems. Trends in Ecology \& Evolution 12(9): 352-356. DOI: 10.1016/So169-5347(97)01133-6

Wen L, Dong S, Li Y, et al. (2013) Effect of degradation intensity on grassland ecosystem services in the Alpine Region of Qinghai-Tibetan Plateau, China. PLoS ONE 8(3): e58432. DOI:10.1371/journal.pone.0058432

White R, Murray S, Rohweder M (2000) Pilot Analysis of Global Ecosystems: Grassland Ecosystems. World Resources Institute, Washington D.C., USA. ISBN: 1569734615, 9781569734612

Xiang S, Guo R, Wu N, et al. (2009) Current status and future prospects of Zoige Marsh in Eastern Qinghai-Tibet Plateau. Ecological Engineering 35(4): 553-562.DOI: 10.1111/j.13652664.2011.01965.x

Yang ZY, Jiang XL (2002) The harm of plateau pika on grassland vegetation and its control threshold value. Pratacultural Science 19(4): 63-65. (In Chinese).

$\mathrm{Yu} \mathrm{H}$, Luedeling $\mathrm{E}, \mathrm{Xu} \mathrm{J} \mathrm{(2010)} \mathrm{Winter} \mathrm{and} \mathrm{spring} \mathrm{warming}$ result in delayed spring phenology on the Tibetan Plateau. Proceedings of the National Academy of Sciences of the United States of America (PNAS) 107(51): 22151-22156. DOI: 10.1073/pnas.1012490107

Zhang Y, Welker JM (1996) Tibetan alpine tundra responses to simulated changes in climate: Aboveground biomass and community responses. Arctic and Alpine Research 28(2): 203-209. DOI: $10.2307 / 155176$

Zhang Z, Pech R, Davis S, et al. (2003) Extrinsic and intrinsic factors determine the eruptive dynamics of Brandt's voles Microtus brandti in Inner Mongolia, China. Oikos 100(2): 299-310. DOI: 10.1034/j.1600-0706.2003.11810.x

Zhao QF, Wang G, Li QX, et al. (2006) Genetic diversity of five Kobresia species along the eastern Qinghai-Tibet plateau in China. Hereditas 143: 33-40. DOI: 10.1111/j.2006.0018-0661. 01924.x

Zhou H, Zhao X, Tang Y, et al. (2005) Alpine grassland degradation and its control in the source region of the Yangtze and Yellow Rivers, China. Grassland Science 51(3): 191-203. DOI: $10.1111 / j .1744-697 X .2005 .00028 . x$ 